\title{
Reflexões em torno de experiências de incubação de empreendimentos de economia solidária em espaços universitários ${ }^{1}$
}

Fabio Jardel Gaviraghi², Walter Frantz ${ }^{3}$

\begin{abstract}
Resumo
O presente artigo propõe analisar como as incubadoras sociais universitárias, no seu processo de incubação, têm significado a autogestão, a empregabilidade e os movimentos sociais. Busca-se verificar a contribuição desse movimento no enfrentamento das refrações da questão social, a partir do conflito entre capital e trabalho, da dominação econômica que eleva a pobreza, o analfabetismo e o desemprego. Reaparecem, nesse contexto, os empreendimentos de economia solidária que buscam gerar trabalho e renda, seguindo os princípios da autogestão e da cooperação em suas atividades de produção, comercialização e troca de produtos. As incubadoras sociais universitárias (ISUs) têm como propósito fomentar e assessorar esses grupos na perspectiva de viabilização da sustentabilidade socioeconômica e na formação política dos cooperados. Após a realização de uma pesquisa qualitativa, aplicação de um formulário semiestruturado em quatro empreendimentos de economia solidária e a quatro ISUs, todos localizados no estado do Rio Grande do Sul, seguindo o método dialético crítico e utilizando a técnica de análise de conteúdo, pode-se concluir que o processo de incubação envolve situações de amplo direcionamento, dentre as quais, a estruturação e organização desses grupos com o objetivo de ocupar um espaço no mercado formal de trabalho, fomentando a empregabilidade, a formação para a autogestão e cooperação com características emancipatórias, significando esse processo como um espaço de mobilização coletiva, de articulação de esforços com o propósito de viabilizar a geração de trabalho e renda.
\end{abstract}

\section{Palavras-chave}

Trabalho. Questão Social. Economia Solidária. Incubadoras Sociais Universitárias.

1. Para atender aos objetivos desse trabalho, serão utilizados os dados buscados através da pesquisa de doutoramento em Educação nas Ciências na Universidade Regional do Noroeste do Estado do Rio Grande do Sul. Durante a realização do doutorado, realizou-se um estágio sanduíche na Universidade de Coimbra, com bolsa CAPES. Destaca-se que a pesquisa passou pelo crivo do comitê de ética da Universidade.

2. Doutor em Educação nas Ciências pela Universidade Regional do Noroeste do Estado do Rio Grande do Sul, Brasil; professor da Universidade Federal de Santa Maria, Rio Grande do Sul, Brasil. E-mail: gaviraghiufsm@ gmail.com.

3. Pós-Doutor em Ciências Sociais Aplicadas pela Universidade do Vale do Rio dos Sinos, Rio Grande do Sul, Brasil; professor titular da Universidade Regional do Noroeste do Estado do Rio Grande do Sul, Brasil. E-mail: wfrantz@unijui.edu.br. 


\title{
Reflections on incubation experiences of solidarity economy enterprises in university spaces
}

\author{
Fabio Jardel Gaviraghi*, Walter Frantz**
}

\begin{abstract}
This article aims to analyze how university-based social incubators, in their incubation processes, have defined self-management, employability and social movements, in order to verify the contribution of this movement in facing the refractions of social issues, supported by dialectical and historical materialism. The process of expanding the conflict between capital and labor is revisited, as well as the elements that reinforce the external economic dominations that increase poverty, illiteracy and unemployment. In this context, solidarity economy projects reappear. They seek to generate work and income by following the principles of self-management and cooperation in their activities of production, commercialization and exchange of products. The purpose of university-based social incubators is to promote and advise these groups in the perspective of the feasibility of socioeconomic sustainability and the political training of their members. After conducting a qualitative research, with the application of a semistructured form together with four projects of solidarity economy and four ISUs located in the State of Rio Grande do Sul, Brazil and using the technique of content analysis we found that this process involves situations of broad orientation, training members, qualified, in some occasions, to occupy a space in the formal labor market, fomenting employability. On the other hand, to a large extent, incubation has provided training for self-management and cooperation with emancipatory characteristics, defining this context as a space of collective mobilization, generation of work and income, articulated with social movements.
\end{abstract}

\section{Keywords}

Labor. Social Issues. Solidarity Economy. University-based Social Incubators.

\footnotetext{
* PhD in Education in the Sciences, Regional University of Northwest of State of Rio Grande do Sul, Brazil; professor at Universidade Federal de Santa Maria, State of Rio Grande do Sul, Brazil. E-mail: gaviraghiufsm@ gmail.com.

* Postdoctoral graduated in Applied Social Sciences, Vale do Rio dos Sinos University State of Rio Grande do Sul, Brazil; professor at Regional University of Northwest of State of Rio Grande do Sul, Brazil. E-mail: wfrantz@ unijui.edu.br.
} 


\section{Introdução}

A estrutura social brasileira tem suas raízes históricas no processo de colonização, especialmente, no longo período da escravatura. Nesse processo, forjaram-se as contradições sociais, políticas e econômicas fundamentais, ainda, inerentes ao desenvolvimento da sociedade brasileira (FERNANDES, 1975). Pode-se dizer que a estrutura social brasileira, até hoje, expressa essas contradições e delas nascem forças, no sentido da manutenção ou da transformação da ordem estabelecida. Entretanto, não se pode desconhecer ou minimizar as demais questões internas e ainda atuais, relativas à dinâmica e ao jogo de interesses contrários, no cenário do desenvolvimento da economia brasileira (FURTADO, 1974).

Podem-se reconhecer, no processo da dinâmica dessas contradições, atualmente, as inúmeras refrações da questão social, dentre elas a pobreza, o analfabetismo, a fome, o desemprego e até mesmo a persistência do trabalho escravo (GELEDES, 2016). Além disso, é importante reconhecer que, no processo histórico de constituição do sistema capitalista mundial, a economia brasileira ocupou um lugar periférico e tributário (WALLERSTEIN, 2007). Pode-se dizer que desse amplo processo decorrem também "marcas" de sujeição inconsciente, quase que indeléveis e de difícil superação, presentes na cultura, no comportamento político e na ordem econômica da sociedade brasileira. $\mathrm{Na}$ visão de Guattari (2000), a essência capitalista não se reduz apenas à "extração" da maisvalia econômica, mas também à sujeição da cultura, das subjetividades, através de sistemas e meios dissimulados de comunicação. Talvez isso ajude a entender, atualmente, no Brasil, as manifestações contra as políticas públicas pela inclusão social, por parte de pessoas que, objetivamente, poderiam ser favoráveis, considerando suas posições na estrutura social.
Entretanto, observam-se, também, no contexto dos debates e das iniciativas nascidas das contradições, movimentos de contestação da ordem política e econômica hegemônica vigente que têm como sua matriz motora a reação à lógica do mercado capitalista. Inicialmente, essas iniciativas eram denominadas associações ou cooperativas, e depois, já na década de 1990, com maior ênfase, foram nominadas como organizações de economia solidária. Essas organizações aparecem como uma forma diferente de produzir, comprar e vender aquilo que é necessário para viver, não de modo que não explore terceiros e respeite o meio ambiente em suas atividades, bem como, constituindose como espaços de movimento, formação e organização política (SINGER; SOUZA, 2000).

Os empreendimentos de economia solidária, em função das suas (im)possibilidades, têm se apoiado em instituições que desenvolvem ações de assessoria e consultoria, de formação e qualificação, que objetivam contribuir na organização e manutenção da viabilidade socioeconômica dessas organizações. As universidades, através das incubadoras sociais (ISUs), estãopromovendoaincubaçãodosgrupos, orientando a sua estruturação, organização, formação e qualificação, englobando aspectos técnicos de natureza contábil e econômica, mas também, por vezes, na perspectiva de ampliação da qualidade de vida dos envolvidos. As formações propostas, entretanto, têm desafios e direcionamentos distintos, ocorrendo muitas vezescom basenos princípios da educação popular, envolvendo-se com os movimentos sociais, promovendo ou reforçando a autogestão e a cooperação. Por outro lado, a formação, em alguns momentos, de forma planejada ou não, segue os preceitos da empregabilidade, que qualifica o trabalhador e até mesmo a equipe técnica para vender a força de trabalho e/ou constituir um empreendedor individual, sendo 
complacente, desta forma, com a organização científica do trabalho utilizada desde a terceira onda $^{4}$ de desenvolvimento industrial, que ampliou as manifestações da questão social.

Precipuamente o objetivo desta reflexão é analisar como as incubadoras sociais universitárias, no seu processo de incubação, têm significado a autogestão, a empregabilidade e os movimentos sociais, com vistas a verificar a contribuição desse movimento no enfrentamento das refrações da questão social.

Para problematizar essa realidade será, na sequência, apontada a base teórica que ilumina esse debate, bem como alguns dados da pesquisa realizada com as incubadoras sociais universitárias, no Estado do Rio Grande do Sul, que dão visibilidade a esse contexto problematizado.

\section{Economia solidária e incubadora social universitária: textos e contextos}

As questões sociais, especialmente relacionadas ao mundo do trabalho, no caso do Brasil, ainda possuem como referência o histórico da colonização e da dominação externa, exemplificados por Florestan Fernandes (1973) Reportando-se somente ao mais recente padrão de dominação externa, ainda em vigência, no Brasil, cita-se a grande expansão das empresas nos países latino-americanos, que representa o capitalismo corporativo e monopolista através dos mecanismos financeiros, ligando-se a sócios locais, às vezes, por meio da corrupção ou outras formas de pressão. Isso promove um imperialismo total, que controla a tecnologia, a educação, a comunicação e consumo em massa, expedientes financeiros, a política nacional e até mesmo a natalidade (RBA, 2013).

Esse controle "imperial" é disseminado por meio da globalização econômica e da adoção pelos governos do aporte teórico neoliberal. Esse modelo econômico, centrado no novo liberalismo, permite e impõe que as taxas de retorno do capital sempre se mantenham superiores àquelas de retorno ao trabalho, como afirma Piketty (2014), o que permite o reforço das antigas refrações da questão social, bem como a geração de novas desigualdades sociais e o analfabetismo forçado, o que torna o

4. O estabelecimento de novas formas de produção ocorre, especialmente, por meio de três ondas de desenvolvimento industrial. A primeira ocorre na Inglaterra, ainda no século XVIII, e tem como característica o ramo têxtil, o algodão, a siderurgia, substituindo os processos de trabalhos artesanais pela máquina a vapor, iniciando-se a mecanização do trabalho e o surgimento das fábricas, estradas de ferro, consolidando o capitalismo industrial (GOERCK, 2006). "A revolução industrial assinala a mais radical transformação da vida humana já registrada em documentos inscritos" (HOBSBAWM, 1983, p. 13). A segunda onda de desenvolvimento industrial, séculos XIX e XX, ocorreu com a utilização do petróleo e da eletricidade, tendo como finalidade a intensificação da acumulação do capital, através do desenvolvimento dos setores de transporte, comunicação da produção em série, tendo como precursores Henry Ford e Frederick W. Taylor, que iniciaram as conhecidas fases Taylorista e Fordista (GOERCK, 2006), que tinham como característica a separação entre a execução e concepção. A terceira onda de desenvolvimento industrial inicia-se em meados da década de 1970 do século XX. Com a crise do sistema anterior, adotam-se as estruturas que utilizam as microeletrônicas, novas formas de produção e novos tipos de automação, pela flexibilização dos processos de trabalho, desenvolvimento do setor terciário, setor de serviços, trabalho em casa (DEDDECA, 2000), passando da máquina como ferramenta para a máquina autorregulada, exigindo profissionais altamente qualificados e polivalentes, apenas em funções mais abstratas e intelectuais (IANNI, 1999).

5. Fernandes (1973) fala sobre o processo de dominação externa de forma ampla ao se reportar sobre a América Latina e englobar a subordinação econômica, política e cultural existente nessa região geográfica. A primeira onda iniciou-se no antigo sistema colonial que durou aproximadamente três séculos. O segundo sistema de dominação tinha como proposição conquistar e controlar, tendo no comércio o seu núcleo central. A terceira se deu através da revolução industrial, tendo o capitalismo como uma realidade histórica. A quarta ocorre por meio do domínio das grandes corporações financeiras. 
desemprego estrutural com novas características e limitações no seu enfrentamento.

Importa referir Piketty (2014, p. 27), quando este afirma que "a história da distribuição da riqueza jamais deixou de ser profundamente política", em que são divergentes e convergentes as forças desestabilizadoras que promovem a desigualdade e não possuem um processo natural ou espontâneo para impedir que a mesma aconteça. Para o autor, a educação tem papel central para reverter esse contexto, porém, entre as linhas de divergência e convergências em relação à divisão das rendas do trabalho e capital, ocorre à difusão do conhecimento. Mesmo sendo muito potente, às vezes pode ser "contrabalançada e dominada por outras forças que operem no sentido contrário, as de divergência, isto é, na direção do aumento da desigualdade" (PIKETTY, 2014, p. 29).

Eric Hobsbawm (2007, p. 11), ao abordar sobre globalização, entende que ela

é acompanhada de mercados livres, atualmente tão em voga, trouxe consigo uma dramática acentuação das desigualdades econômicas e sociais, no interior das nações e entre elas. Não há indícios de que essa polarização não esteja prosseguindo dentro dos países, apesar de uma diminuição geral da pobreza extrema. Este surto de desigualdade, especialmente em condições de extrema instabilidade econômica com as que se criaram com os mercados livres globais desde a década de 1990, está na base das importantes tensões sociais e políticas do novo século.

Essa realidade tem permitido um controle específico que, além de contribuir na concentração de renda, tem afastado a população do controle econômico e político dos espaços em que reside, o que tem ampliado as refrações da questão social. Esta, "sendo desigualdade é também rebeldia, por envolver sujeitos que vivenciam as desigualdades e a ela resistem e se opõem" (IAMAMOTO, 2012, p.
28), tem o seu cerne enraizado no conflito entre capital e trabalho - suscitado entre a compra efetuada pelos donos dos meios de produção e a venda da força de trabalho pelos trabalhadores - e gera, assim, o desemprego. É através da rebeldia e da resistência que manifestam, por ser a maneira que os sujeitos encontram para se "opor e resistir às desigualdades, como, por exemplo, conselhos de direitos, sindicatos, políticas, associações, programas e projetos sociais" (FRAGA, 2010, p. 45), podendo adicionar-se a própria economia solidária.

Bauman (2005, p. 19) em seu livro Vidas desperdiçadas afirma que desemprego "é o nome de uma condição claramente temporária e anormal". Segue afirmando que a noção de desemprego trouxe sua "carga semântica da autoconsciência de uma sociedade que costumava classificar seus integrantes, antes de tudo, como produtores, e também acreditava no pleno emprego não apenas como condição desejável e atingível, mas também como seu derradeiro destino".

Culti (2000, p. 118) entende que "para amenizar a questão do desemprego e oferecer oportunidades para aqueles que estão socialmente excluídos, é importante criar alternativas reais de reinserção". Alternativas que podem ser ações pontuais, provisórias ou permanentes, mas que permitem uma organização inicial para a manutenção e sobrevivência de seus integrantes ou como espaço de movimento e luta de constituição de poder de ação.

Os empreendimentos de economia solidária surgem, nesse contexto, como uma alternativa de geração de trabalho e renda e com o propósito de "(re)afirmar o espaço social alicerçando dinâmicas de subsistência para além das fronteiras econômicas, haja vista que suas contribuições atingem as esferas sociais, políticas e ambientais" (BORGES; SCHOLZ; ROSA, 2014, p. 68). Para Santos (2014, p. 2), o surgimento das iniciativas de economia 
solidária, em especial após os anos de 1990, no Brasil, "representa a emergência de um processo social, econômico, político e cultural que tem despertado a atenção de pesquisadores de várias áreas do conhecimento". As inúmeras pesquisas, debates, organizações sociais e políticas têm demonstrado e buscado compreender essas diferentes percepções e realidades que englobam a o surgimento e fortalecimento da denominada "economia solidária".

Nesse mesmo direcionamento, Gaiger (2009, p.181) entendequea economia solidáriaé

originada da livre associação de trabalhadores, nas quais a cooperação funciona como esteio de sua eficiência e viabilidade [...]. Esses empreendimentos adotam, em proporção variável, arranjos coletivos na posse dos meios de produção, no processo de trabalho e na gestão dos empreendimentos, minimizando a presença das relações assalariadas.

A economia solidária tem por base quatro pontos que são centrais na sua caracterização (SINGER, 2001). São eles: a cooperação, que é a "existência de interesses e objetivos comuns"; autogestão, que se apresenta quando "exercitam as práticas participativas de a autogestão dos processos de trabalho, das definições estratégicas e cotidianas dos empreendimentos, da direção e coordenação das ações nos seus diversos graus e interesses etc"; a dimensão econômica, que é "uma das bases de motivação da agregação de esforços e recursos pessoais e de outras organizações para produção, beneficiamento, crédito, comercialização e consumo"; a solidariedade, que se apresenta na justa distribuição dos resultados que foram alcançados e "nas oportunidades que levam ao desenvolvimento de capacidades e da melhoria das condições de vida dos participantes; no comprometimento com um meio ambiente saudável", bem como, "na preocupação com a comunidade local e no respeito aos direitos dos trabalhadores e trabalhadoras" (BRASIL, 2015).

São inúmeros os desafios que são impostos aosempreendimentos deeconomiasolidáriapara atingir esses pontos centrais, especialmente pela inserção no mercado capitalista e da presença dos valores conservadores que têm motivado os associados a buscar assessoria para viabilizar essas organizações coletivas. Encontramse, nesse processo, as incubadoras sociais universitárias que, através de uma equipe técnica de incubação, vêm assessorando e fomentando esses grupos. Essa aproximação ocorreu pela demanda dos empreendimentos, mas, também, após um processo de questionamento interno das próprias instituições de ensino superior sobre o papel da universidade frente à pobreza existente na sociedade (CRUZ, SANTOS, 2008).

As universidades têm papel central na organização da sociedade contemporânea, especialmente por serem espaços privilegiados de produção de conhecimento que, em tese, têm por objetivo contribuir para a existência de uma sociedade que preconize o desenvolvimento justo e igualitário. Para tanto, desde a Constituição Federal de 1988, as universidades têm dentre seus princípios a indissociabilidade entre o ensino, a pesquisa e a extensão, tripé central na promoção da educação superior (FRANTZ, 2010).

Para Fraga (2012, p. 19), as incubadoras sociais universitárias ${ }^{6}$ são constituídas por

6. “As incubadoras tecnológicas de cooperativas populares (ITCPS), cumprem papéis de extrema importância no campo da Economia Solidária. Primeiramente elas capacitam os empreendimentos, tirando muitos deles da informalidade e da precariedade e propiciando uma renda digna a seus participantes. Um segundo papel é o de articular novas políticas públicas no campo da geração de trabalho e renda" (FILHO; CUNHA, 2009, p. 224). Importa mencionar que as incubadoras sociais universitárias possuem basicamente a mesma composição e organização, ou seja, dentre seus integrantes estão docentes, técnicos em assuntos educacionais e acadêmicos de graduação e pós-graduação. Mesmo existindo um coordenador ou uma equipe coordenadora, a gestão da ISU ocorre, em sua grande maioria, de forma compartilhada e autogestionada, utilizando-se de reuniões de planejamento, inclusive com os associados que estão em incubação, para definir os projetos a serem desenvolvidos. 
grupos de professores/as, estudantes e técnicos administrativos que atuam junto a grupos populares (cooperativas/associações/grupos informais) "com intuito de assessorá-los em suas atividades de produção, comercialização e de organização política". Observa-se que existe, através das ISUs, uma integração entre segmentos de recursos humanos estruturantes da universidade, os quais desenvolvem o processo de incubação por meio de reuniões, palestras, oficinas, encaminhamentos para políticas públicas, atividades de formação, atividades de planejamento e avaliação, entre outras, que, de forma articulada, propositiva e formativa, fomentam os empreendimentos de economia solidária.

A incubação, termo utilizado pelas ISUs para definir suas ações, para Moura (2014, p. 9) "consiste em uma aventura, pois implica o esforço de articulação de inúmeros campos disciplinares, estabelecendo conexões entre universos densos, profundos e diversificados". Para Coimbra e Souza (2007, p. 6), as incubadoras foram instituídas "como uma resposta da universidade brasileira aos problemas sociais relacionados ao trabalho". Destacam as autoras que as incubadoras possuem como objetivo "organizaremse para oferecer suporte à formação e ao desenvolvimento de experiências de geração de trabalho e renda, sob a forma de coletivos de trabalhadores em situação de desemprego, com vínculos precários ou em vulnerabilidade social", mas que buscam acessar um trabalho baseado em outras relações, não o de subordinação. As incubadoras sociais universitárias possuem como objetivo:

Incentivar a formação de empreendimentos de Economia Solidária como alternativa para a geração de trabalho, renda e redução da exclusãosocial; produzir, disseminaretransferir conhecimentos sobre Economia Solidária, de forma transdisciplinar, tornando os acessíveis à sociedade; capacitar multiplicadores para a difusão e desenvolvimento de conhecimentos produzidos na universidade, visando à criação de assessoria aos empreendimentos solidários; introduzir nos programas institucionais da universidade, de forma indissociada, os princípios e objetivos da Economia Solidária; assessorar técnica, administrativa e politicamente, de forma integrada e continuada, grupos sociais interessados na criação e fortalecimento de empreendimentos solidários, visando a sua autonomia; incentivar a formação de Redes de Cooperação voltada para o fortalecimento da Economia Solidária [...]. (BRASIL, 2011, p.76).

Além disso, a formação que é proposta pelas incubadoras sociais universitárias aos empreendimentos pode e tem contribuído na sistematização do conhecimento que é "indispensável à luta popular [...], mas esse conhecimento deve percorrer os caminhos da prática [...], pois esse se dá à reflexão dos corpos humanos que estão resistindo e lutando, apreendendo e tendo esperança" (FREIRE; NOGUEIRA, 2013, p. 41).

Para atingir seus objetivos, as incubadoras, se valem de metodologias que orientam as atividades formativas e de assessoria. Esse caminho adotado é problematizado na sequência.

\section{A incubação: empregabilidade, autogestão e movimentos sociais}

A construção da metodologia de incubação, para atingir viabilidade econômica e/ou política de forma mais ampla, segue um caminho específico que tem sido utilizado pela grande maioria das incubadoras. Os componentes apontados por Eid (2004), utilizando-se de autores como Culti (2000), Melo Neto (2002) e Eid e Gallo (2001), afirmam que a incubação deve seguir uma lógica, que se inicia com avaliação da implantação das própria incubadoras. Após, segue com o desenvolvimento da incubação 
nas suas etapas (pré-incubação, incubação e pós-incubação). Na sequência, promove-se a avaliação participativa dos empreendimentos em incubação (fatores de desenvolvimento, crise, sucesso, insucesso, redefinição de estratégias), bem como o intercâmbio das incubadoras e seus empreendimentos, com o objetivo de construir redes de economia solidária.

Para Rebehy, Belissímo e Caldana (2016), a metodologia de incubação consiste em um conjunto de atividades que garante, através de metodologias participativas, a consideração do saber popular e a troca de conhecimentos. Os autores afirmam que essas metodologias constituem um instrumento de comunicação, que, por sua vez, normatizam os conjuntos sequenciais e as ações que serão desenvolvidas com os grupos.

Um dos desafios enfrentados por esses núcleos
que se dedicam à economia solidária é
desenvolver métodos de incubação capazes de
viabilizar não apenas a existência de coletivos
organizados para o trabalho, mas, também,
seu funcionamento como células efetivamente
autogestionárias e comprometidas com os
princípios orientadores da economia solidária
e a inserção dessas células em complexas
redes de relações que envolvem outros
empreendimentos solidários, outros atores
sociais da economia solidária, e mesmo no
mercado capitalista, pouco amistoso a essa
forma de organização do trabalho e gestão.
(COUTINHO, 2005, p. 4).

Como destacado por Coutinho (2005), as incubadoras são desafiadas a encontrar um método de incubação que tenha condições de viabilizar a existência dos coletivos. Entre os caminhos adotados para esse fomento, comprometendo-se com a economia solidária, está o reforço da autogestão e a articulação, em termos de atividades práticas e de formação, com os movimentos sociais, que objetivam a defesa dos aspectos econômicos, bem como das identidades étnicas ou de igualdade de gênero dos envolvidos.

A autogestão ${ }^{7}$, que se apresenta como conceito na década de 1950 pelo Partido Comunista luguslavo (MOTHÉ, 2009), caracteriza este novo tipo de cooperativismo, sendo reveladora de "uma nova concepção de democracia e de cidadania" (LECHAT, 2006, p. 139). A história da sociedade da antiga Iugoslávia tem, em sua base, debates e experiências de autogestão que foram referência aos esforços por visualizar alternativas de organização de trabalho produtivo, sob controle dos trabalhadores (HORVAT, 1972).

A autogestão é reforçada em experiências de incubação, como um caminho metodológico, justamente pelo seu caráter agregador de interesses e responsabilidades, de modo que evita que esses empreendimentos possam, no decorrer dos anos, seguir princípios das empresas capitalistas de organização hierárquica com patrões e empregados, se tornando, assim, "organizações cooperativas" somente em sua denominação jurídica e não em seus princípios. Mesmo sendo a autogestão um princípio central, as ISUs devem promover esse debate nas associações ou cooperativas e também na própria equipe "operadora da incubação", para que essa forma de organização não se distancie da realidade e dos objetivos de seus integrantes.

O objetivo da autogestão é romper com a tradição centralizada, burocratizada e antidemocrática, estabelecendo um novo modo de organização social e produtiva, onde os indivíduos assumem a responsabilidade sobre suas atividades, sem intermediários. Baseia-se, pois, na decisão coletiva dos sujeitos envolvidos, seja uma cooperativa, associação, banco popular ou grupo produtivo. Com a autogestão, todos são responsáveis pelo sucesso ou fracasso, pois as informações

7. [...] um projeto de organização democrática que privilegia a democracia direta. Esta constitui um sistema em que voluntariamente, sem perceberem remuneração e sem recorrerem a intermediários, os cidadãos debatem todas as questões importantes, em assembleias (MOTHÉ, 2009, p. 26). 
são socializadas, os saberes são respeitados e a decisão é coletiva, independente de escolaridade, gênero, raça, etnia e orientação sexual. (PESSOA et al., 2008).

Além desse fator, a articulação no processo de incubação, com os movimentos sociais, também passa a ser um dos caminhos adotados pelas incubadoras, justamente por ser um espaço de caráter organizativo e combativo. Destaca Galvão (2008), que os movimentos sociais, especialmente os originários na década de 1990, surgiram em contraponto ao neoliberalismo e de forma ampla, pois se constituíram com o envolvimento de jovens, mulheres e trabalhadores urbanos, com foco no movimento econômico, mas também pertencendo ao movimento em defesa da identidade étnica, de minorias, de gênero, entre outros. A autora aponta ainda que a composição dos movimentos, como no caso brasileiro do Movimento dos Trabalhadores Rurais Sem Terra (MST), inclui desempregados urbanos, trabalhadores informais e camponeses expulsos de suas terras. Ou seja, os movimentos são compostos por trabalhadores que são ou poderiam ser integrantes dos empreendimentos de economia solidária e vinculados às incubadoras e que retroalimentam a própria universidade em seu modo de ser e se fazer.

Gohn (2013), ao se referir ao MST, aponta o processo educativo de natureza sociopolítica que esses movimentos, considerados mais antigos pela autora, desenvolviam ou estão desenvolvendo. Esse movimento passa a ser um instrumento de mobilização e organização popular, como um "processo permanente de aprendizagem a partir da prática, geradora de processos organizativos e de consciência social nas classes populares" (GOHN, 2013, p. 42).

A educação popular como campo de conhecimento e prática educativa presente nos movimentos e, por vezes, nas incubadoras, se constituiu em exercício permanente de crítica ao sistema vigente, bem como de contraposição ao padrão de sociabilidade que é por ele difundida. A educação popular foi construída através de luta e resistência das classes populares, sendo formulada e vivida na América Latina, enquanto concepção educativa que vincula explicitamente a educação e a política, na busca de contribuir para a construção de processos de resistência e para a emancipação humana, o que requer uma ordem societária que não é regida pelo capital (PALUDO, 2015, p. 220). Assim, se vinculam e entrelaçam práticas de educação popular e práticas de incubação, isto é, das incubadoras sociais universitárias.

Para Valêncio et al. (2000, p. 97), as incubadoras apresentam-se não apenas como uma ação sincrônica ao crescente desemprego presente no Brasil, mas é também uma ação emancipadora, "sobretudo se vista como uma resposta de superação ao debate acerca das condições de empregabilidade da população economicamente ativa".

Gentili (2002, p. 54) destaca que, neste novo século, as economias podem crescer de forma a excluir e multiplicar a discriminação de muitas pessoas, adotando o discurso da empregabilidade, o qual desvaloriza o princípio universal do direito ao trabalho e valoriza, especialmente, a "lógica competitiva interindividual na disputa pelo sucesso num mercado estruturalmente excludente".

A empregabilidade compreende a capacidade do indivíduo de

se ajustar aos requisitos postos por um mercado de trabalho que deverá se caracterizar por mudanças contínuas, provocadas pela obsolescência de algumas ocupações, pelo surgimento de novas ocupações e pelo job enrichment. (FOGAÇA, 2003, p. 65).

Alberto (2005, p. 5) entende que a noção de empregabilidade tem sido usada como uma "premissa de que os indivíduos devem acreditar que o reiterado retorno à escola 
seria a garantia de inserção e permanência no mundo do trabalho", ou seja, que a "educação geraria a segurança no trabalho". Afirma ainda a autora, que o processo de mundialização do capital tem limitado a integração dos indivíduos à vida produtiva, revogando a ideia de que o aprendizado contínuo garante, mesmo que de forma flexível, a empregabilidade. Segundo a autora, dados da realidade comprovam que muitas pessoas tituladas estão desempregadas, o que reforça o discurso conservador de que o responsável pela falta de trabalho é o próprio indivíduo, de forma a culpabilizar os trabalhadores "por sua incapacidade de transformar sua força de trabalho em valor de uso, mesmo depois de ter tido possibilidade de agregar mais valor a ela mediante o acesso à educação".

Nesse contexto, as incubadoras sociais universitárias são desafiadas a fomentar atitudes autogestionárias e solidárias que contribuam à inserção ao mundo do trabalho, acesso a emprego e renda.

\section{As incubadoras sociais universitárias: dados de realidade e projeções}

Para a presente reflexão sobre incubadoras sociais universitárias foram realizadas pesquisas bibliográficas, buscados e aproveitados dados de pesquisa de campo. A pesquisa teve como problema central observar como as incubadoras sociais universitárias, através do processo de incubação, projetam e/ou significam a perspectiva da educação popular na formação dos atores envolvidos e no enfrentamento das manifestações da questão social no Rio Grande do Sul. Entre os conteúdos das entrevistas estavam: caracterização das incubadoras, metodologia(s) utilizada(s), processos de trabalho e formação proposta aos integrantes das ISUs e EES, observando os preceitos da educação popular, políticas públicas, movimentos sociais e sua relação com as ISUs, entre outras que possibilitaram algumas reflexões, dentre elas compreender a relação entre autogestão (ao observar as formas de organização dos empreendimentos e como eram implementados os princípios da economia solidária), empregabilidade (diferenças entre princípios e valores da economia solidária e do mercado formal de trabalho) e movimentos social (envolvimento com os seguintes movimentos sociais: Movimento de luta pela terra, Movimentos em defesa da política de saúde mental, Movimento da economia solidária, entre outros).

Trata-se de uma pesquisa qualitativa, que seguiu o método dialético crítico e foi realizada por meio de entrevistas e aplicação de formulários com quatro incubadoras e quatro empreendimentos incubados, cujo objetivo foi analisar como as incubadoras sociais universitárias estão significando e/ou projetando a educação popular no enfrentamento das refrações da questão social. Os dados foram analisados a partir da técnica de análise de conteúdo, baseada em Bardin (2011).

A partir dos dados da pesquisa, podese observar que a $\mathrm{IS}^{8}{ }^{8}$, ao discorrer sobre a experiência da incubação e a metodologia utilizada nesse processo, evidencia que o

8. Código para identificar as Incubadoras Sociais Universitárias pesquisadas. As incubadoras pesquisadas possuem como características centrais o envolvimento direto de seus atores com a economia solidária e seu movimento, internalizando, para dentro dos muros da universidade, os conhecimentos já produzidos e sistematizados nas comunidades locais onde estão localizados os EES. Duas incubadoras pesquisadas são vinculadas a universidades federais e outras duas a universidades comunitárias, permitindo, assim, observar os desafios que são postos em ambos os espaços. Entre os segmentos dos EES que estão em incubação e visitados para a realização da referida pesquisa, estão: pequenos agricultores que produzem produtos orgânicos, catadores de materiais recicláveis, grupos de produção que têm entre seus associados usuários da Política de Saúde Mental e grupo de mulheres de produção de sabão. 
trabalho desenvolvido com os grupos rurais é "realmente inspirador", pois nesse espaço realizam-se vivências dos bolsistas ${ }^{9}$ com os grupos de economia solidária e o "fato é que os agricultores sabem muito mais de agroecologia do que os estudantes que vão lá trabalhar com eles", diz o coordenador, referente à incubação desenvolvida junto ao MST. Assim, o envolvimento com os movimentos sociais tem colaborado com a própria equipe de incubação, ocorrendo uma "psicologia reversa", segundo o coordenador da IS1, onde os integrantes do MST estão sendo formados, mas também formando acadêmicos e, demais integrantes da equipe técnica de incubação, sobre temáticas que possuem experiência, oportunizando a valorização dos princípios da educação popular, e, portanto, de enfrentamento das refrações da questão social.

As incubadoras sociais universitárias aproximam-se também dos movimentos por interesse desses, justamente pela capacidade da equipe da universidade em sistematizar o conhecimento e organizar os trabalhadores para ampliar as possibilidades de geração de trabalho e renda e reivindicar, por exemplo, direitos sociais aos usuários da política de saúde mental, um segmento assessorado pelas incubadoras pesquisadas.

Essa articulação com os movimentos é significada também por meio do fortalecimento da organização dos catadores de materiais recicláveis, especialmente das mulheres, que estão se organizando para enfrentar a fome, o analfabetismo e o desemprego, que são refrações com maior presença nas comunidades onde estão inseridos esses empreendimentos de catação e reciclagem. Foi possível observar que se busca, através dessa aproximação, dar visibilidade à desigualdade de gênero e etnia ainda frequentes na sociedade brasileira, ao reforçar, nas formações, o papel da mulher e seu reconhecimento como chefes de família.

O coordenador da IS $2^{10}$ cita a organização política das mulheres integrantes de um empreendimento em incubação, bem como se refere aos jovens.

A economia invisível das mulheres camponesas, elas queriam saber quanto vale o trabalho de ordenha da vaca, cuidar da horta enquanto o marido está lá na roça. A gente fez um longo trabalho de formação com elas, um ou dois anos a gente ficou juntos e elas, resultou em uma pesquisa, dessa pesquisa elas fizeram uma cartilha para o movimento, agora a economia solidária que deve isso para se fortalecer e realmente se transformar em um movimento capaz de conquistar, para sair além do seu empreendimento, para além das salas dos fóruns, além das salas das entidades de apoio, ela poder ter algum reconhecimento, ela precisa se organizar com os movimentos, o fórum gaúcho tem feito essa discussão, tenho achado muito legal, principalmente com a juventude, temos que conquistar a juventude e para isso tem que investir na cultura, a gente tem que abrir.

A IS3 tem entre suas atividades a articulação com o movimento dos catadores de materiais recicláveis, com o objetivo de qualificar e ampliar a participação destes nos espaços políticos e reivindicatórios, inclusive de enfrentamento do próprio poder público. Destaca o coordenador que está sendo um desafio promover a articulação entre "catadores" e o poder público. Segundo ele, os gestores atualmente se entendem como "donos da

9. Bolsistas de iniciação científica, de pesquisa ou extensão que participam das atividades das ISUs.

10. Importa mencionar que as incubadoras pesquisadas foram selecionadas por meio da amostra intencional, seguindo critérios como: ter desenvolvido as três etapas da metodologia tradicional de incubação (pré-incubação, incubação e pós-incubação (desincubação); ter vinculação com a alguma Rede de incubadoras; ter entre seus integrantes acadêmicos de graduação e/ou pós-graduação; desenvolver atividades contínuas e não somente sazonais etc. Entre os entrevistados, estavam especialmente os gestores, por vezes, com a participação de integrantes das equipes técnicas. 
situação", existindo, assim, um "enfrentamento da base popular com a gestão pública; quando a gestão pública manda em você nas reuniões, que são de organização política fica complicado". Revela-se, de certo modo, um conflito de interesses: a incubadora querendo mobilizar os catadores, montar uma estratégia para melhorar a relação associativa e cooperativa entre catadores, ampliar sua interlocução com os demais apoiadores, melhorar a coleta seletiva e, segundo o coordenador entrevistado, o "poder público vinha com uma demanda própria dela, vinha discutir somente por que a coleta não era discutida nas empresas $X$ e $Y$, vinham apenas com cobranças", solicitando um serviço sem pensar na lógica da cooperação e autogestão, presentes, em tese, na economia solidária.

Já estão presentes nessas ações o fortalecimento da autogestão e da emancipação, pois, como manifesta a IS3, faz-se importante a valorização desses princípios para que os empreendimentos possam ter autonomia plena, sem vínculo eterno à incubadora. Afirma o coordenador entrevistado: "Quando você acompanha meio distante e você vê os passos deles [...] observa que o grupo se mantém, o empreendimento está se mantendo, não está entrando em crise, não está com dívidas, e está se posicionando politicamente", pode-se afirmar que o grupo se constituiu de maneira autogestionária. Para atingir esse patamar, destaca o entrevistado, deve-se, nos processos de formação, promover desconstruções de muitas coisas que já estavam postas, "ouvindo muito eles [...] a incubação não é fazer por eles, incubação é fazer com eles, ensinar a turma, para que depois eles consigam fazer sozinhos".

Para ampliar esse debate e reforçar a existência de princípios que se aproximam da autogestão, o coordenador da IS3 fala das estagiárias do curso de graduação em administração de empresas, que desenvolviam ações de fluxos de caixa e não entendiam o motivo da não aceitação dessa atividade no grupo. "Professor, eu montei toda uma planilha linda de fluxo de caixa, eu cheguei lá e eles não querem. Quem disse que eles querem fluxo de caixa? Mas o professor da disciplina falou que um fluxo ajudaria a cooperativa. Eles fazem tudo num caderno, mas entendem". A autogestão apresenta-se na contestação das ações da própria equipe de incubação, inclusive ao mostrar a importância de serem os seus princípios efetivados na própria equipe da incubadora.

Por outro lado, as ações de incubação são observadas pelos associados e, por vezes, pela própria equipe de incubação, como um mecanismo de qualificação, por meio de cursos de corte e costura, de panificação, de informática, entre outros, que poderão contribuir com os associados a encontrar uma vaga no mercado formal de trabalho, reproduzindo a ideia da empregabilidade e, por vezes, culpabilizando os trabalhadores por vivenciarem a realidade da pobreza e do desemprego.

A coordenação da IS4 relata que foram realizados dezoito cursos formativos para os seus empreendimentos em incubação. Entretanto, após estarem aptas para o desenvolvimento da produção de forma coletiva, com conhecimento técnico, muitas associadas se retiraram e se tornaram empreendedoras individuais, inclusive, com agradecimentos à incubadora. A coordenadora da incubadora afirma que os valores impregnados na cultura e o comportamento das pessoas podem não ser "superados" com as ações de incubação. Segundo o relato, elas assim se manifestam, após cursos de formação: "Sabe, aquilo tudo que vocês ensinaram pra nós dá certo, eu já tenho três gurias vendendo pra mim, eu pago $\mathrm{R} \$ 15,00$ por dia para cada uma delas".

Umdosentrevistados dosempreendimentos, quando questionado sobre a importância das ações de incubação, afirmou:

Hoje as pessoas estão aqui porque arrumar 
emprego, com essa crise, está bem difícil. Então aqui é um meio das pessoas ganharem uma renda, não é uma renda como a da empresa, porque é um pouco diferenciado, mas também é uma alternativa de sustentar uma família e a casa (EES3).

Entre os exemplos da reprodução de valores e princípios que culpabilizam os trabalhadores pela condição de desempregado, cita-se a fala de uma integrante de uma equipe técnica que apresentava esse entendimento, mas que compreendeu seu equívoco no decorrer do processo, talvez, fruto das formações internas desenvolvidas.

Elas trabalhavam inicialmente em uma sede da igreja, era tipo um galpão de festa, uma associação de moradores, logo no início elas tinham reforço escolar nos outros dias, então elas tinham três dias da semana que elas podiam produzir, era o único espaço que elas tinham, e ai, era uma terça feira, era feriado e elas iam fazer feriado, e aí a gente falava porque, elas nunca têm venda e vão fazer, vão ter uma venda e vão fazer feriado, então a gente se deu por conta que elas eram trabalhadoras e se todos os trabalhadores tem feriado, porque elas não podem, todo mundo gosta de feriado, eu sempre tive feriado, então porque elas não podem (IS4).

Observa-se que, mesmo nesse "(des) caminho", as incubadoras estão atentas a problematizar essa realidade e buscam construir passagens seguras e concretas para o enfrentamento e superação das refrações da questãosocialquesãoreproduzidasefomentadas, historicamente, na sociedade brasileira.

\section{Algumas considerações}

As incubadoras sociais universitárias, no seu processo de incubação, têm direcionado suas ações de forma articulada com os movimentos sociais de abrangência econômica e formativa, como o MST e o movimento de catadores e de organização das mulheres que, além de gerar trabalho e renda, defendem a igualdade de gênero. Elas têm reforçado a autogestão como princípio, pois os empreendimentos incubados têm se organizado, questionado o poder público e a própria equipe de incubação, no decorrer do processo de suas atividades nas ISUs. Também têm debatido sobre empregabilidade, buscando oposição a esse entendimento em suas formações, reforçando que o empreendimento não consiste apenas em um espaço transitório para o ingresso no mercado formal de trabalho. Desta forma, essas incubadoras têm contribuído para a viabilização dos empreendimentos de economia solidária e, consequentemente, para o enfrentamento do desemprego, da pobreza e de outras refrações da questão social.

Como se observou, o artigo apenas problematizou, de forma reduzida e limitada, os direcionamentos e as opções de metodologia utilizadas nas ações de incubação. Importa referir que as refrações da questão social não são recentes e possuem natureza ampla, não sendo possível, obviamente, por meio da incubação, enfrentá-las em condições de superação plena. No entanto, são momentos em que se plantam sementes, que germinam consciências políticas deenfrentamento equestionamento da realidade e de oportunidades para que trabalhadores desempregados possam problematizar e reivindicar a criação de políticas sociais públicas.

A autogestão e a articulação com os movimentos sociais apresentam-se como caminhos por serem espaços de formação, de valorização da educação popular, mas também por permitirem aos integrantes da equipe da universidade uma formação fora dos muros das instituições de ensino superior, para além da sala de aula, por meio das ações de extensão, como foi destacado pela IS1.

As incubadoras sociais universitárias, historicamente, são jovens e ainda precisam lançar mais a fundo suas bases, porém estão se constituindo em um importante caminho de 
aproximação entre comunidade e universidade ao ampliar a função social desta para com o local de sua inserção, reafirmando sua importância e contribuição para a construção de uma nova sociedade. É assim que esses caminhos se significam, buscando promover a incubação para além da empregabilidade, promovendo enfrentamentos políticos, apresentando a economia solidária aos que não a entendem como uma alternativa, mostrando também que a universidade é uma importante fomentadora, por ser um espaço de formação, porém não é a única alternativa, não estará resolvendo todas as "situações problemas".

\section{Referências}

ALBERTO, M. A. A noção da empregabilidade nas políticas de qualificação e educação profissional no Brasil nos anos 90. Revista Trabalho, Educação e Saúde, Rio de Janeiro, v. 3, n. 2, jan.-set. 2005. doi: http://dx.doi.org/10.1590/S1981-77462005000200004.

BARDIN, L. Análise de conteúdo. São Paulo: Edições 70, 2011. 229 p.

BRASIL. Ministério do Trabalho e Emprego. Economia solidária. 2015. Disponível em: <http:// trabalho.gov.br/trabalhador-economia-solidaria >. Acesso em: 20 abr. 2016.

BAUMAN, Z. Vidas desperdiçadas. 3. ed. Tradução de Carlos Medeiros, Rio de Janeiro: J. Zahar, 2005. $176 \mathrm{p}$.

BORGES, M. de L.; SCHOLZ, R. H.; ROSA, G. F. Produção de sentido do trabalho para recicladores por meio da ressignificação da identidade, aprendizagem e superação. In. SCHOLZ, R. H. (Org.). Economia Solidária e Incubação: uma construção coletiva de saberes. São Leopoldo: Oikos, 2014. p. 60-82.

BRASIL. Ministério do Trabalho e Emprego. Avaliação Nacional do Programa de Incubadoras Tecnológicas de Cooperativas e Empreendimentos Solidários (PRONINC): relatório final. Recife: IADH, 2011. $337 \mathrm{p}$.

COIMBRA, A. L. de S.; SOUZA, M. B. de. Princípios e ações em economia solidária: a Intecoop/ UFJF e o cooperativismo popular com egressos do sistema penitenciário de Juiz de Fora/MG. Proposta: Revista Trimestral de Debate da Fase, Rio de Janeiro, Ano 31, n. 112, 2007.

COUTINHO, M. C. et al. Novos caminhos, cooperação e solidariedade: a psicologia em empreendimentos solidários. Revista Psicologia \& Sociedade [online], Belo horizonte, v. 17, n. 1, p. 17-28; jan.-abr. 2005. Disponível em: <http://www.mobilizadores.org.br/wp-content/ uploads/2014/05/novos-caminhos-cooperao-e-solidariedade.pdf >. Acesso em: 12 jan. 2017. doi: http://dx.doi.org/10.1590/S0102-71822005000100002.

CRUZ, A., SANTOS, A. M. Incubadoras tecnológicas de cooperativas populares: interdisplinariedade articulando ensino, pesquisa e extensão universitária. E-cadernos CES [online], dez. 2008. Disponível em: <http://eces.revues.org/1354 >. Acesso em: 10 jan. 2017. doi:http://dx.doi. org/10.4000/eces.1354.

CULTI, M. N. Sócios do suor: cooperativas de trabalho. In: PRIORI, A. (Org.). O mundo do trabalho 
e a política: ensaios interdisciplinares. Maringá: Eduem, 2000. p. 113-137.

DEDDECA, C. S. As mudanças no sistema das relações de trabalho. Diplô BRASIL: Caderno de Debates do Le Monde Diplomatique. Edição brasileira especial "Globalização e mundo do trabalho", v. 1, set. 2000. p. 4-6.

EID, F. Análise sobre processos de formação de incubadoras universitárias da Unitrabalho e metodologia de incubação de EES. In: PICANÇO, I.; TIRIBA, L. (Orgs.). Trabalho e Educação. Aparecida, SP: Ideias \& Letras, 2004. p. 167-188.

EID, F., GALLO, A. R. Metodologia de incubação e desafios para o cooperativismo popular: uma análise sobre o trabalho da Incubadora de Cooperativas Populares da UFSCar. In: SEMINÁRIO DE METODOlOGIA DE PROJETOS DE EXTENSÃO - SEMPE, 2001, São Carlos. Anais... São Carlos: Editora da UFSCar, 2001.

FERNANDES, F. Capitalismo dependente e classes sociais na América Latina. Rio de janeiro: J. Zahar, 1973. $151 \mathrm{p}$.

A revolução burguesa no Brasil: ensaio de interpretação sociológica. Rio de Janeiro: J. Zahar, 1975. 413 p.

FOGAÇA, A. Educação e qualificação profissional no anos 90: o discurso e o fato. In: OLIVEIRA, D. A.; DUARTE, M. R. T. (Orgs.) Políticas e trabalho na escola: administração dos sistemas públicos de educação básica. Belo Horizonte: Autêntica, 2003, p. 55-68.

FURTADO, C. Formación económica del Brasil. 2. ed. México: Fondo de Cultura Económica, 1974. 259p.

FRAGA, C. K. A atitude investigativa no trabalho do assistente social. Serviço Social \& Sociedade, São Paulo, n. 101, p. 40-64, jan.-mar. 2010. doi: http://dx.doi.org/10.1590/S010166282010000100004.

FRAGA, L. S. Extensão e transferência de conhecimento: as incubadoras tecnológicas de cooperativas populares. 2012. 242f. Tese (Doutorado em Política Científica e Tecnológica) - Instituto de Geociências, Universidade Estadual de Campinas, Campinas, 2012.

FRANÇA FILHO, G. C.; CUNHA, E. V. Incubação de redes de economia solidária. In: CATTANI, A. D. et al. (Orgs.). Dicionário internacional da outra economia. São Paulo: Almedina, 2009. p. 224-230.

FRANTZ, W. Desafios à Universidade no espaço das práticas sociais. In. BARCELOS, E. S., RASIA, P. C., SILVA, E. W. (Orgs.). Economia Solidária: sistematizando experiências. Ijuí: Editora da Unijui, 2010. p. 65-84.

FREIRE, P.; NOGUEIRA, A. Que fazer: teoria e prática em educação popular. 15. ed. Petrópolis, RJ: Vozes, 2013. 68 p.

GAIGER, L. I. Empreendimento econômico solidário. In: CATTANI, A. D. et al. (Orgs.). Dicionário internacional da outra economia. São Paulo: Almedina, 2009. p. 181-187. 
GALVÃO, A. Os movimentos sociais da América Latina em questão. Revista Debates, Porto Alegre, v. 2, n. 2, p. 8-24, jul.-dez. 2008.

GELEDES Instituto da mulher negra. O trabalho escravo é uma realidade no Brasil. E não há uma pessoa presa por isso. 2016. Disponível em: <http:/www.geledes.org.br/o-trabalho-escravo-euma-realidade-no-brasil-e-nao-ha-uma-pessoa-presa-por-isso/?gclid=CIWFm4mZ3dICFRcJkQodT 1slzA\#gs.tVeP1tl>. Acesso em: 17 mar. 2017.

GENTILI, P. Três teses sobre a relação trabalho e educação em tempos neoliberais. In. LOMBARDI, J. C.; SAVIANI, D; SANFELICE, J. L. (Orgs.) Capitalismo, trabalho e educação. Campinas, SP: Autores Associados, 2002. (Coleção Educação Contemporânea).

GOERCK, C. Emergência do cooperativismo, reestruturação do capital e economia solidária e o papel do serviço social em empreendimentos solidários. ljuí: Editora da Unijuí, 2006. (Cadernos Unijuí: Série Economia Solidária).

GONH, M. da G. Educação popular e movimentos sociais. In: STREK, D. R.; ESTEBAN, M. T. (Orgs.). Educação popular: lugar de construção coletiva. Petrópolis: Vozes, 2013. p. 33-48.

GUATTARI, F; ROLNIK, S. Micropolítica: cartografias do desejo. Petrópolis, RJ: Vozes, 2000. 439 p. HOBSBAWM, E. Globalização, democracia e terrorismo. São Paulo: Cia. das Letras, 2007. 182 p. 1983. 349 p.

Da revolução industrial inglesa ao imperialismo. Rio de Janeiro: Forense Universitária, HORVAT, B. Die jugoslawische gesellschaft: ein essay. Frankfurt am Main: Suhrkamp Verlag, 1972.

IAMAMOTO, M. V. O serviço social na contemporaneidade: trabalho e formação profissional. 22. ed. São Paulo: Cortez, 2012. 326 p.

IANNI, O. O mundo do trabalho. In: FREITAS, M. C. de. (Org.). A reinvenção do futuro: trabalho, educação, política na globalização do capitalismo. 2. ed. São Paulo: Cortez, 1999. 207 p.

LECHAT, N. M. P. As raízes históricas da economia solidária e seu aparecimento no Brasil.. ljuí: Editora da Unijuí, 2006. (Cadernos Unijuí: Série Economia Solidária).

MOTHÉ, D. Autogestão. In: CATTANI, A. D. et al. (Orgs.). Dicionário internacional da outra economia. São Paulo: Almedina, 2009. p. 26-30.

MOURA, E. P. G. de. O que estamos fazendo quando incubamos? In: SCHOLZ, R. H. (Org.). Economia solidária e incubação: uma construção coletiva de saberes. São Leopoldo: Oikos, 2014. p. 9-24.

PALUDO, C. Educação popular como resistência e emancipação humana. Cad. Cedes, Campinas, v. 35, n. 96, p. 219-239, 2015. Disponível em: <http://www.scielo.br/pdf/ccedes/v35n96/16787110-ccedes-35-96-00219.pdf>. Acesso em: 26 fev. 2017.

PESSOA, C. et al. Economia solidária e feminista: reflexões em torno da autonomia econômica das mulheres. 2008. Disponível em: < http://www.socioeco.org/bdf_fiche-document-108_pt.html>. Acesso em: 8 abr. 2016. 
PIKETTY, T. O capital no século XXI. Rio de Janeiro: Intrínseca, 2014. 976 p.

RBA - Rede Brasil Atual. A face oculta do investimento estrangeiro. 2013. Disponível em: <http:// www.redebrasilatual.com.br/revistas/33/a-face-oculta-do-investimento-estrangeiro $>$. Acesso em: 18 jan. 2017.

REBEHY, P. C. P. W.; BELLISSIMO, D. Y.; CALDANA, A. C. F. A metodologia de uma incubadora tecnológica de empreendimentos solidários (ITES): instrumento de promoção de inovação e empreendedorismo? RACEF, Ribeirão Preto, v. 7, n. 1, p. 187-204, 2016. Disponível em: < https:// www.fundace.org.br/revistaracef/index.php/racef/article/view/233>. Acesso: 20 fev. 2017. doi: http://dx.doi.org/10.13059/racef.v7i1.233.

SANTOS, A. M. Os dilemas da organização popular no movimento da economia solidária no Brasil. Otra Economia, São Leopoldo, v. 8, n. 15, 2014. Disponível em: < http://revistas.unisinos.br/index. php/otraeconomia/article/view/otra.2014.815.07> . Acesso em: 10 jan. 2017.

SINGER, P. Globalização e desemprego: diagnóstico e alternativas. 5. ed. São Paulo: Contexto, 2001. 139 p.

SINGER, P.; SOUZA, A. R. (Orgs.). A economia solidária no Brasil: a autogestão como resposta ao desemprego. São Paulo: Contexto, 2000. 360 p.

VALÊNCIO, N. F. L. da S. et al. Incubadora de cooperativas populares: uma alternativa à precarização do trabalho. 2000. Disponível em: <http://www.uff.br/incubadoraecosol/docs/ ecosolv1.pdf>. Acesso em: 7 ago. 2016.

WALLERSTEIN, I. M. O universalismo europeu: retórica do poder. São Paulo: Boitempo, 2007. $137 \mathrm{p}$.

Submetido em 20 de março de 2017.

Aprovado em 13 de julho de 2017. 